\title{
AOR
}

Selected Papers of \#AolR2020: The $21^{\text {st }}$ Annual Conference of the Association of Internet Researchers Virtual Event / 27-31 October 2020

\section{ONE OF THESE THINGS IS LIKE THE OTHERS: WHAT BIG TECH PLATFORMS CAN LEARN FROM LIBRARIES, BOOKSTORES, AND SUPERMARKETS}

Caitlin Petre

Rutgers University

Nicole Weber

Rutgers University

In November 2018, Facebook CEO Mark Zuckerberg announced the formation of an "Oversight Board" for the platform, the purported goal of which is "safeguarding free speech and protecting people's safety" on the platform (Facebook, 2019, p. 4). The move was heralded by some as a promising first step to correct Facebook's historically laissez-faire approach to violent, abusive and otherwise objectionable content; others have argued that Facebook's move to establish the board raises more questions than it answers about how the company envisions and wields its governance role (Douek \& Klonick, 2019).

Whatever shape the oversight board ultimately takes, its very creation illustrates the mounting pressure on large technology platforms to grapple with their outsize influence over the contemporary public sphere. Platforms are mired in high-profile controversies - concerning misinformation, disinformation and "fake news"; harassment and violent threats; algorithmic profiling and discrimination; the decimation of the business model for traditional news sources, and many other issues - that have opened up vital conversations about the governance of these spaces. What role, if any, does a company like Facebook have in supporting a healthy public sphere that facilitates democratic self-governance (see, e.g., Myers-West 2017, Ananny 2018)? How might platforms reconcile their private interests with the public good? And though what kinds of techno-organizational infrastructures and shared value systems might this reconciliation be accomplished?

While versions of these questions have long been fundamental to democracies with heavily marketized media systems, existing scholarship typically focuses on the ways in which large technology platforms play an unprecedented role in the public sphere. This emphasis is not entirely misplaced: these companies do indeed possess unique

Suggested Citation (APA): Petre, C., Weber, N.. (2020, October) One of These Things Is Like the Others: What Big Tech Platforms Can Learn from Libraries, Bookstores, and Supermarkets. Paper presented at AolR 2020: The 21 $1^{\text {th }}$ Annual Conference of the Association of Internet Researchers. Virtual Event: AolR. Retrieved from http://spir.aoir.org. 
features that may necessitate novel governance frameworks, such as their sheer size and scale, as well as their reliance on automated moderation and ranking to sort usergenerated content (see, e.g., Gorwa, Binns and Katzenbach 2020).

Yet as we consider what appropriate platform governance might look like, our article argues that there is also value in considering the ways in which platforms like Facebook are similar to previous generations of information intermediaries. Their distinctive features notwithstanding, digital platforms are hardly the first institutions to produce, curate, and organize information and knowledge. The premise of our paper is that there are lessons to be learned from the way in which platforms' predecessors have made (or failed to make) curatorial, organizational, and governance decisions. Specifically, we use a comparative case study approach to examine three institutions that have historically inhabited a structural position in the public information landscape that is similar to large technology platforms: libraries (Hoffman 2016), bookstores (Miller 2008), and supermarket magazine racks. Each of these three cases has contended with variations of the questions that technology platforms are now struggling to address; exploring how they have imagined and performed their role as information intermediaries promises to spur new thinking on key issues of platform governance.

The study maps several considerations each of these intermediaries have faced in order to develop a typology of approaches to information curation and moderation. For example, when controversial cases of information management arise, are processes for adjudicating conflicting interests formal or improvised? With their strictly for-profit orientation, supermarkets have traditionally taken an ad hoc approach similar to that of tech platforms, removing materials from magazine racks only in response to an extreme public outcry, as when they temporarily stopped selling celebrity tabloids following Princess Diana's death (See Cunningham, 1997; Noah, Devlin, \& Solomon, 1997). Libraries, however, emulate an entirely different model: systematized book challenge processes, which attempt to address public concerns about materials (Slocum, 2018), and regular "weeding" (or culling) of their collections to better serve the public (Vnuk 2015). Bookstores fall somewhere in between, as they attempt to balance their profit motive with their curatorial role (Miller 2008).

In developing this typology, our article does not seek to dictate a roadmap for platforms. Yet considering the ways that platforms' constraints and challenges overlap with those of other longstanding information intermediaries allows us to identify common problems and possible solutions for platforms moving forward. By examining a variety of oftoverlooked approaches to information curation and outlining their respective benefits and drawbacks, we hope to contribute a historical and conceptual perspective to scholarly and industry conversations about platform governance.

\section{References}

Ananny, Mike. (2018). Networked Press Freedom: Creating Infrastructures for a Public Right to Hear. Cambridge, MA: MIT University Press. 
Cunningham, W. J. (1997 Sept 13). GROCERS SHOULDN'T BE CENSORS. Retrieved June 13, 2019, from Greensboro News and Record website:

https://www.greensboro.com/grocers-shouldn-t-be-censors/article 00942036-1ce85dad-b51f-4f34e3a705a9.html

Douek, E. \& Klonick, K. (2019 June). Facebook Releases an Update on Its Oversight Board: Many Questions, Few Answers. Lawfare.

https://www.lawfareblog.com/facebook-releases-update-its-oversight-board-many-

questions-few-answers

Facebook, "Global Feedback \& Input on the Facebook Oversight Board for Content Decisions" (2019). https://fbnewsroomus.files.wordpress.com/2019/06/oversight-boardconsultation-report-2.pdf

Gorwa, R., R. Binns, and C. Katzenbach. (2020). Algorithmic content moderation: Technical and political challenges in the automation of platform governance. Big Data \& Society https://doi.org/10.1177/2053951719897945.

Hoffman, A. L. (2016). Privacy, Intellectual Freedom, and Self-Respect: Technological and Philosophical Lessons for Library. Perspectives on Libraries as Institutions of Human Rights and Social Justice. (Advances in Librarianship, Vol. 41): 49-70

Miller, L. J. (2008). Reluctant capitalists: Bookselling and the culture of consumption. University of Chicago Press.

Myers-West, S. (2017). "Searching for the Public in Internet Governance: Examining Infrastructures of Participation at NETmundial." Policy \& Internet 10(1): 22-42.

Noah, P., Devlin, F., \& Solomon, W. (1997). Stores remove tabloids* several area grocery chains pull star, national enquirer from shelves. Retrieved June 13, 2019, from https://www.mcall.com/news/mc-xpm-1997-09-15-3155273-story.html

Slocum, R. (2018, September 4). Back to School: A Guide to Preparing Your Library for Book Challenges. Retrieved June 13, 2019, from Intellectual Freedom Blog website: https://www.oif.ala.org/oif/?p=15304

Vnuk, R. (2015). The weeding handbook: a shelf-by-shelf guide. American Library Association. 